\title{
La autotutela, derecho comparado en México
}

\section{The Self-Protection, Comparative Law in Mexico}

Rolando Castillo Santiago* https://orcid.org/0000-0001-8764-9168

http://dx.doi.org/10.21503/lex.v17i23.1675

* Profesor investigador de la Universidad Juárez Autónoma de Tabasco, abogado postulante, maestro en Derecho y doctor en Estudios Jurídicos, miembro del PNPCCONACYT, México.

Correo electrónico: myc_abogado@me.com
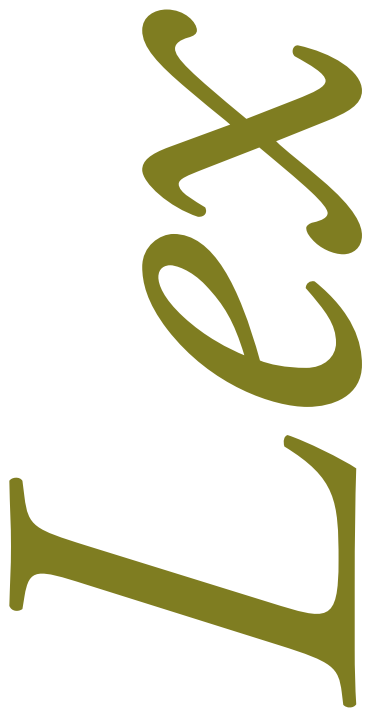


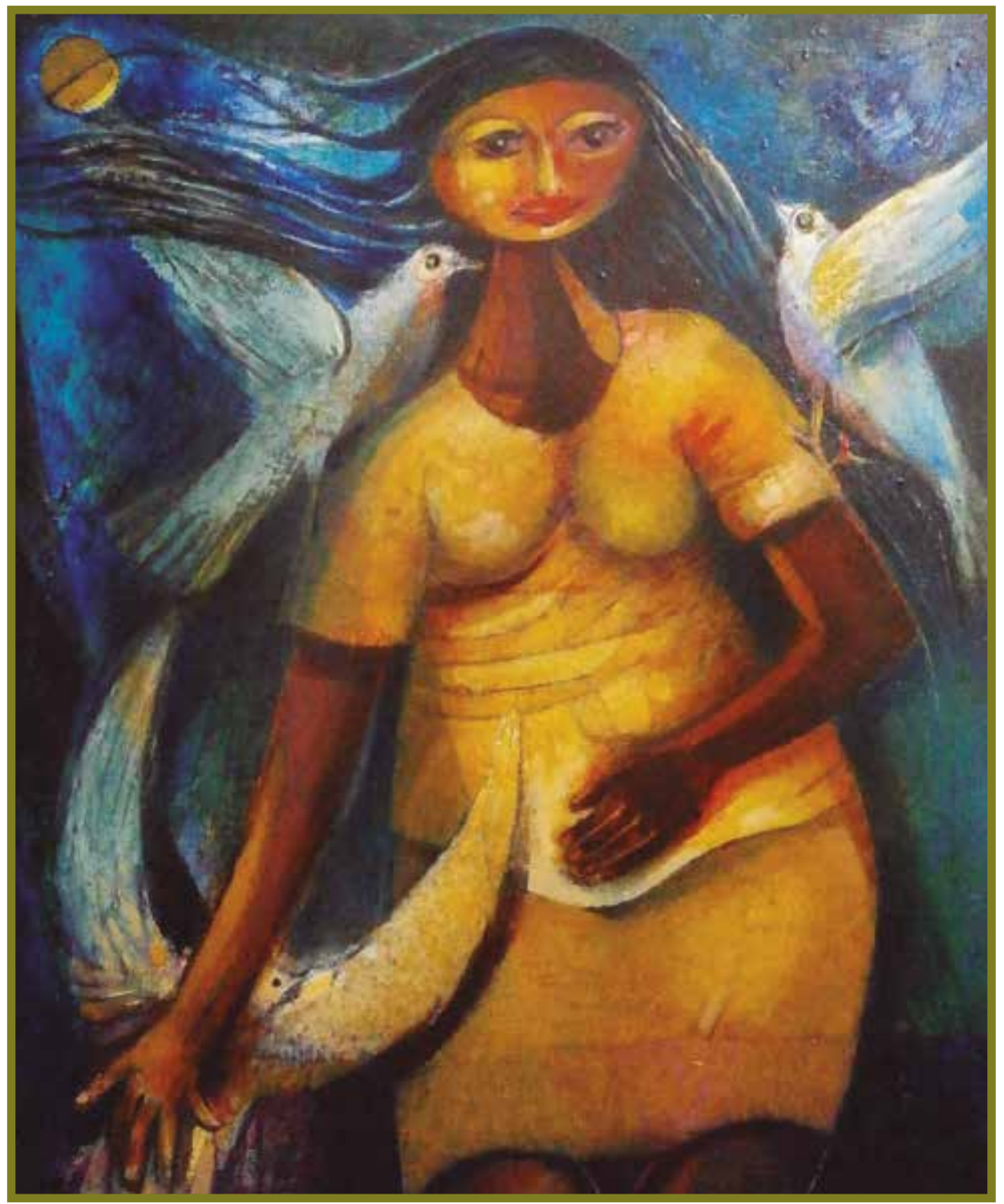

Mujer con paloma en azul. Óleo 60 x $52 \mathrm{~cm}$.

Agustín Aquino Mejías (pintor peruano). 


\section{RESUMEN}

La Legislación Espańola contempla una serie de figuras impulsadas y reguladas en los últimos tiempos con el fin de proteger el patrimonio y el bienestar de las personas con discapacidad o incapaces, destacando la figura de la autotutela. Este es un medio en el cual una persona, con capacidad de goce y ejercicio, puede establecer, mediante la formalidad de escritura pública suscrita ante la fe de un notario, quién o quienes serán responsables de su cuidado en caso de una futura incapacidad, así como tomar disposiciones en torno a sus derechos u obligaciones. A pesar de algunos avances que en la materia presenta el cuerpo jurídico mexicano, ante la falta de una figura equivalente en nuestro país, se analiza su necesidad, su posible regulación y sus efectos.

Palabras clave: autotutela, capacidad, notario, persona, incapacidad, ejercicio, derecho, patrimonio, formalidad.

\section{ABSTRACT}

The Spanish Law considers many figures promoted and lately ruled in order to protect the estate and wellbeing of disabled or handicapped persons emphasizing the self-protection figure as a means for the person with full possession of faculties to place on public record signed upon a Notary Public who would be responsible of his/her care in the occurrence of a future disability and also to set instructions regarding his/her rights and obligations. In spite of some progress shown by the Mexican law, the lack of an equivalent figure in our country leads to the analysis of its necessity, possible regulation and effects.

Key word: self-protection, ability; notary; person; disability, exercise; right; estate; formality. 
Destaca en primer lugar la regulación de la autotutela, es decir, la posibilidad que tiene una persona capaz de obrar de adoptar las disposiciones que estime convenientes en previsión de su propia futura incapacitación, lo cual puede ser especialmente importante en el caso de enfermedades degenerativas. ${ }^{.}$

\section{INTRODUCCIÓN}

Dentro del marco sustantivo del Derecho espańol, ha cobrado relevancia un conjunto de disposiciones englobadas dentro de la figura jurídica llamada "testamento vital" (living will), que tienen por objeto permitir que se cumplan los deseos o voluntad materialmente posibles de una persona, en momentos en que quien lo ejerce no está en condiciones físicas o mentalmente posibles para pronunciarse o ejercer su voluntad.

Concretamente, los instrumentos admitidos y regulados por la normatividad española son tres:

a) El documento de voluntad anticipada. ${ }^{2}$

b) La delación de la autotutela. ${ }^{3}$

c) El apoderamiento preventivo. ${ }^{4}$

1 Exposición de motivos de la Ley 43/2003, de Protección Patrimonial de las Personas con Discapacidad, publicada el 18 de noviembre de 2003, acceso: octubre de 2015, http://www.boe.es/buscar/act.php?id=BOE-A-2003-21053, quinto párrafo. Entró en vigor en España el 20 de noviembre de 2003.

2 Figura jurídica presente en el Derecho Mexicano desde el 07 de enero de 2008, fecha en la que se publicó la Ley de Voluntad Anticipada para el Distrito Federal, a la que le ha seguido la Ley de Voluntad Anticipada para el Estado de Hidalgo del 14 de febrero de 2011 y la Ley de Voluntad Anticipada del Estado de México del 03 de mayo de 2013. Coahuila, Aguascalientes, Chihuahua, San Luis Potosí, Guanajuato, Michoacán, Nayarit, Guerrero y Colima son otros estados que han incorporado esta figura en su normativa vigente. Se espera que a mediano plazo otros estados de la República también la incorporen.

3 Figura que se analiza en el presente artículo.

4 La cual aún no ha cobrado forma en el Derecho mexicano, en el que por la vía judicial se nombra tutor para el incapaz. 
El instrumento de voluntad anticipada consiste en el documento público suscrito ante notario, en el que cualquier persona con capacidad de ejercicio y en pleno uso de sus facultades mentales, manifiesta la petición libre, consciente, seria, inequívoca y reiterada de no someterse a medios, tratamientos y/o procedimientos médicos, que propicien la Obstinación Médica, buscando se proteja en todo momento la dignidad de la persona. ${ }^{5}$

En México el documento de voluntad anticipada busca regular la ortotanasia, ${ }^{6}$ no permitiéndose ninguna medida que tenga como fin disminuir intencionalmente el período de vida.

Debe contar con las siguientes formalidades y requisitos:

a) Realizarse de manera personal, libre e inequívoca ante la fe de notario.

b) En caso de no poder acudir ante notario por alguna razón médica, puede ser firmado ante el personal de salud y dos testigos según el formato emitido por la Secretaría de Salud.

c) El nombramiento de un representante para corroborar la realización del documento de voluntad anticipada; el cargo es libre y gratuito.

d) Manifestación expresa respecto a si desea ser o no donador de órganos.

e) Una vez realizado el documento, es deber del notario notificarlo a la comisión especializada en la materia, quién a su vez dará vista al Ministerio Público.

Resulta destacable que las leyes de la materia vigentes en México contemplan la posibilidad de que el personal de salud a cargo de la persona que ha firmado un documento de voluntad anticipada se excuse de cumplir su voluntad por creencias religiosas o convicciones personales (objetores de conciencia), exigiéndose que en los centros médicos exista en todo momento personal disponible y capacitado para cumplir su voluntad, señalando que también se prohíbe de forma expresa la eutanasia.

En el Derecho español, tal acto consiste en la declaración expresa sobre el destino o la forma de utilizar sus bienes, derecho que ejerce una persona mayor de edad y en plenas facultades, sin impedimento que limite el pronunciarse sobre sus bienes o derechos y que sea materialmente posible, para el caso de que no se encuentre en condiciones físicas o psicológicas, que ejerza su voluntad, señalando las siguientes:

5 Artículo primero de la Ley de Voluntad Anticipada para el Distrito Federal, publicada el 07 de enero de 2008, en Gaceta Oficial del Distrito Federal, acceso: octubre de 2015, http://www.aldf.gob.mx/archivo-077346ece61525438e126242a37d313e.pdf. Entró en vigor al día siguiente de su publicación, sin reformas.

6 Muerte natural de un enfermo desahuciado sin someterlo a una prolongación médicamente inútil de su agonía. Diccionario de la Real Academia de la Lengua Española, acceso: octubre de 2015, http://dle.rae.es/?w=ortotanasia\&o=h 
a) Desea que se le suministren fármacos necesarios para paliar al máximo su dolor y sufrimiento en el caso de una enfermedad irreversible.

b) Desea pasar sus últimos días de vida en su domicilio.

c) Desea ser mantenido con vida hasta que técnicamente sea imposible su supervivencia o si se rehúsa a continuar con vida de forma artificial.

d) Desea donar sus órganos, únicamente para trasplantes, la investigación o la enseñanza.

e) Desea ser incinerado o enterrado, y si desea algún oficio funerario religioso.

f) Desea nombrar un interlocutor o representante que aclare o concrete sus instrucciones.

Formalmente puede hacerse ante notario, ante la persona encargada del registro en los hospitales o ante tres testigos, y ha de inscribirse en el Registro de Voluntades Anticipadas y, en su caso, en el de Donantes de Órganos.

Como se puede observar, la amplitud de la voluntad anticipada en el Derecho español resulta abrumadora al compararla con su similar en la normativa existente en solo algunos Estados y el Distrito Federal de la república mexicana, limitándose en este último caso a salvaguardar la voluntad de la persona y para poder efectuar disposiciones en materia de bienes, para lo cual es necesario un instrumento testamentario.

La delación de la autotutela es la disposición que hace cualquier persona que, previendo perder la capacidad, comparece ante notario a fin de designar quién desea que en el futuro sea su tutor. Lo anterior establece en relación con su persona o bienes, salvaguardando el derecho humano como la dignidad, derechos que deben ser compatibles con cualquier norma o criterio.

El poder preventivo es un poder que, a diferencia de los anteriores, no se extingue por la mera incapacidad del poderdante.

Tal posibilidad fue incluida expresamente en el Art. 1732 del Código Civil, Español, por la, de protección patrimonial de las personas con discapacidad, que establece "el mandato se extinguirá, también, por la incapacitación sobrevenida del mandante a no ser que en el mismo se hubiera dispuesto su continuación o el mandato se hubiera dado para el caso de incapacidad del mandante apreciada conforme a lo dispuesto por este. En estos casos, el mandato podrá terminar por resolución judicial dictada al constituirse el organismo tutelar o posteriormente a instancia del tutor."

Ley 41/2003, de 18 de noviembre, de protección patrimonial de las personas con discapacidad y de modificación del Código Civil, de la Ley de Enjuiciamiento Civil y de la Normativa Tributaria con esta finalidad, publicada el 19 de noviembre de 2003, en Boletín Oficial del Estado n. ${ }^{\circ}$ 277, Departamento Jefatura del Estado, Referencia BOE-A-2003-21053, acceso: octubre de 2015, https://www.boe.es/buscar/act.php?id=BOE-A-2003-21053 


\section{ANTECEDENTES DE LA AUTOTUTELA}

El primer caso al que se puede hacer referencia en nuestro objeto de estudio lo encontramos en el ciudadano ruso Ivon Cnimzo, quien, afectado de una enfermedad hereditaria degenerativa ligada a la edad (a él se le manifestó, tardíamente, a los 24 años, siendo que solía aparecer sobre los 20), decidió, el mismo día en que alcanzaba la mayoría de edad, autorizar un documento privado en el que nombraba tutor a un vecino amigo por si acaso él se volvía loco, como realmente así sucedió finalmente. Ante los tribunales rusos surgió entonces el problema de si una persona mayor de edad podía nombrar o no para el futuro a su propio tutor, cuestión esta que nunca antes había sido planteada hasta entonces. La decisión judicial soviética reconoció definitivamente la legalidad del documento suscrito por Ivon, tanto en su vertiente personal como también en la perspectiva patrimonial.

En el derecho comparado y entre los pocos ordenamientos que admiten el negocio jurídico de la autotutela, cabría citar al código civil suizo, en cuyo Art. 381, in fine, puede leerse lo siguiente: "A menos que justos motivos no se opongan a ello, la autoridad tutelar nombrará tutor a la persona designada por el padre o la madre o por el incapaz". Y en el Derecho alemán se admite que una persona mayor de edad que no pueda valerse por sí misma designe a un asistente o curador (betreuer). Esta designación vinculará al juez que decida sobre la incapacitación, salvo que se estime contrario a sus intereses. Este betreuer tendrá por misión completar la capacidad del sujeto en la medida en que determine la sentencia incapacitadora.

\section{LA TUTELA TESTAMENTARIA Y LA AUTOTUTELA}

En el ámbito de la discapacidad, en sus políticas públicas los estados enfrentan hoy una serie de problemas que se derivan, paradójicamente, de la espectacular evolución científico-técnica y de la mayor calidad de vida que disfrutamos.

El progresivo envejecimiento de la población hace crecer el número de personas dependientes y la incidencia de enfermedades discapacitantes, como el Alzheimer o el Parkinson. Sin olvidar que la mejora de los servicios sanitarios y el imparable avance de la investigación contribuyen también a alargar la vida de las personas con discapacidad. Ese hecho feliz lleva aparejadas consecuencias indeseables: cuando a la discapacidad se le suman factores como el deterioro físico y mental vinculado al envejecimiento, aumentan las necesidades y el grado de dependencia de estas personas. Por otra parte, esta mayor supervivencia determina que, en muchas ocasiones, las personas con discapacidad sobrevivan a sus padres o a sus familiares cuidadores.

Lógicamente, la conjugación de todas estas variables ha generado en las familias una gran preocupación acerca del futuro de la persona con discapacidad, tanto en el aspecto material o económico, como en el relativo a la asistencia y cuidados que van a serle imprescindibles. 
En sentido general, se entiende por autotutela, el negocio jurídico por el que una persona designa a quien quiere que le asista o supla en el supuesto de incurrir en una causa de incapacitación, así como el régimen jurídico de dicha asistencia y constituye, a nuestro juicio, junto con los poderes preventivos o de autoprotección, el instrumento con el que mejor se puede hacer frente a una futura incapacitación.

Dentro de la normatividad española, el tutor de una persona judicialmente incapacitada es designado siempre por el juez, en la misma resolución del procedimiento de incapacitación, o en una resolución posterior, en un procedimiento de jurisdicción voluntaria. Pero hay dos supuestos en el Código sustantivo Civil español, en los que el legislador ordena al juez que tenga en cuenta una voluntad previamente manifestada de los que ejercen su derecho en documento auténtico de testamento. ${ }^{8}$

La primera de las situaciones es la designación de tutor en testamento. El Art. 223-I del Código sustantivo Civil español dice que "los padres podrán, en testamento o documento público notarial, nombrar tutor, establecer órganos de fiscalización de la tutela, así como designar las personas que hayan de integrarlos u ordenar cualquier disposición sobre la persona o bienes de sus hijos menores o incapacitados". El párrafo II del mismo precepto, por su parte dispone que "asimismo, cualquier persona con la capacidad de obrar suficiente, en previsión de ser incapacitada judicialmente en el futuro, podrá en documento público notarial adoptar cualquier disposición relativa a su propia persona o bienes, incluida la designación de tutor”.

La primera situación es muy antigua y se conoce con el nombre de tutela testamentaria. Lo que subyace en esta delación tutelar es el hecho de unos padres con un hijo incapacitado judicialmente, o incapacitable en el futuro (en previsión del momento en que ellos mismos falten) señalan en testamento o en documento notarial distinto del testamento, a quién prefieren (o a quién designan) como tutor de su hijo. Es una manifestación legal que revela la preocupación de todos los padres, de qué será de sus hijos cuando ellos falten.

La autotutela es un instrumento del Derecho Civil que faculta a la persona mayor de edad y con capacidad de obrar, a designar para sí misma, mediante documento público notarial, un tutor o tutores para el caso de que en el futuro devenga incapaz, la referida escritura también puede incluir disposiciones referentes tanto al cuidado de su persona como a la administración de sus bienes. ${ }^{9}$

8 Art. 234 del Código Civil, publicado por el Real Decreto de 24 de julio de 1889, Boletín Oficial del Estado, n. ${ }^{\circ}$ 206 (julio de 1889), referencia BOE-A-1889-4763, acceso: octubre de 2015, http://www.boe.es/buscar/pdf/1889/ BOE-A-1889-4763-consolidado.pdf

9 Carlos Rendón Ugalde, “Fundamentos teóricos y prácticos de la autotutela”, Revista de Derecho Privado, no 11 (2005): 77. 
De la definición dada pueden extraerse fácilmente las notas características de esta figura, a saber: es necesario que la persona que designa tutor para sí misma sea mayor de edad y capaz en el momento de otorgar la escritura. La designación de tutor tiene que hacerse en documento público por exigencia legal; la designación entrará en juego únicamente en el supuesto de que la persona incurra en una incapacidad (prevista o no). Resulta posible incluir en la escritura, además de la designación del tutor o tutores, disposiciones referentes tanto a los bienes como a la persona del posible futuro incapaz.

La doctrina se ha referido a esta de distintas formas, siendo hasta ahora la más aceptada la "autotutela", conociéndosele también como "tutela fiduciaria", 10 "tutela cautelar" "autodelación de la tutela" y "tutela voluntaria".

El primer antecedente histórico conocido de esta figura se remonta a 1921, año en el que Crehuet del Amo pronunció su discurso de ingreso en la Real Academia de Jurisprudencia y Legislación titulado "La tutela fiduciaria" ${ }^{11}$ Posteriormente, en 1924, una Real Orden de 14 de marzo, inserta en el Anuario de la Dirección General de los Registros y del Notariado, dio respuesta a una solicitud en la que se pedía que se declarara eficaz la designación de tutor hecha ante notario por quien preveía su propia incapacidad. La referida orden, si bien consideró que dicha posibilidad podía entenderse implícita en la legislación civil del momento, rechazó la petición alegando la incompetencia de la administración para tratar asuntos propios de los tribunales. ${ }^{12}$

Es concretamente el Art. 9.1 de dicha norma, que modifica la redacción del Art. 223 del Código Civil, el que introduce la figura en el Derecho Común, al pasar a disponer el precepto de que "cualquier persona con la capacidad de obrar suficiente, en previsión de ser incapacitada judicialmente en el futuro, podrá en documento público notarial adoptar cualquier disposición relativa a su propia persona o bienes, incluida la designación de tutor". Asimismo, la nueva redacción del Art. 234 del Código Civil, modificado por el Art. 9.2 de la mencionada ley, dispone que "para el nombramiento del tutor se preferirá: $1^{\circ} \mathrm{Al}$ designado por propio tutelado, conforme al artículo 223".

10 La Ley 41/2003, de 18 de noviembre, en su Art. 9, que modifica el Art. 223 del Código Civil, hace mención a la autotutela y establece que: "cualquier persona con la capacidad de obrar suficiente, en previsión de ser incapacitada judicialmente en el futuro, podrá en documento público notarial adoptar cualquier disposición relativa a su propia persona o bienes, incluida la designación de tutor".

11 Ibidem, 136.

12 Durante los años siguientes, la doctrina se interesó por el tema y se presentaron diversos estudios en defensa de la figura. Por parte de algunos se intentó introducir la autotutela en la Ley 13/1983, de 24 de octubre, de reforma del Código Civil en materia de tutela, pero no se logró. Finalmente, la autotutela fue incorporada al ordenamiento jurídico de la mano de la Ley 41/2003, de 18 de noviembre, de Protección Patrimonial de las personas con discapacidad y de modificación del Código Civil, de la Ley de Enjuiciamiento Civil y de la Normativa Tributaria con esta finalidad. 


\section{EL PATRIMONIO ESPECIALMENTE PROTEGIDO DE LAS PERSONAS CON DISCAPACIDAD}

La autotutela sería una figura jurídica inoperante si no existieran las medidas y condiciones necesarias que garanticen la existencia de un patrimonio que sustente al incapaz. Por ello la legislación española de 18 de noviembre de 2003 ha incorporado importantes modificaciones en el ámbito del Derecho Civil, ${ }^{13}$ con la finalidad de dotar al discapacitado o incapaz de una protección patrimonial íntegra.

La legislación al respecto permite una doble esfera de actuación: una que podemos denominar autoprotección, ${ }^{14}$ y otra, la protección a través del Derecho sucesorio que reforma la autoprotección. Esta se desarrolla en una fase anterior a la discapacitación, mediante actuaciones previsoras como la autotutela o el contrato de alimentos o bien cuando ya existe una situación de discapacidad, mediante la constitución de un patrimonio protegido al amparo de la ley. La regulación detallada e íntegra del patrimonio protegido se mantiene como ley especial frente al código sustantivo español.

$\mathrm{Al}$ referirnos que la ley tiene por objeto regular nuevos mecanismos de protección de las personas con discapacidad, ella está centrada en un aspecto esencial de esta protección: la patrimonial, ya que uno de los elementos que más repercuten en el bienestar de las personas con discapacidad es la existencia de medios económicos a su disposición, suficientes para atender las específicas necesidades vitales de los mismos.

Se regula una nueva figura, la del "patrimonio especialmente protegido de las personas con discapacidad" 15 que una vez constituido, queda inmediata y directamente vinculado a la satisfacción de las necesidades vitales de la persona que padece esta circunstancia. De esta

13 Las políticas de protección o amparo dirigidas a los discapacitados no han de agotarse en medidas públicas: el derecho privado es un instrumento muy adecuado para mejorar la calidad de vida de estas personas y de sus familias. Sin dejar de reconocer que los poderes públicos han de ser la garantía primera y última de la situación de los discapacitados, es necesario también asumir el papel fundamental que desarrollan las familias en esta materia: es innegable el derecho que les asiste de velar por esos miembros discapacitados, de preocuparse por su presente y su futuro.

14 "El derecho de autoprotección. Concepto y estado actual de la cuestión”. Revista del Notariado (julio-septiembre de 1999): 22: "partimos del convencimiento de que todo ser humano en el ejercicio de su más inalienable libertad y del más elemental derecho de propiedad tiene derecho a prever estas cuestiones (autoprotección de su persona y bienes en previsión de su futura incapacitación), como a intentar solucionarlas de antemano y al efecto de dictar y estipular pautas para su gobierno, en el supuesto de que en un futuro ya no pueda hacerlo por sí. En nuestro discurrir, en ningún momento nos asaltaron dudas acerca de la licitud de tales decisiones por parte de todo ser humano respecto de su persona y su patrimonio, tomadas siendo capaz, para ser ejecutadas en una eventual circunstancia de incapacidad..."

15 Se trata de una figura que aprovecha el concepto tradicional de patrimonio separado, con abundantes precedentes en la legislación espańola, y que responde plenamente a esas demandas insistentemente formuladas desde los sectores implicados, pues proporciona un instrumento para la satisfacción de las necesidades de los discapacitados en que se incentiva la iniciativa y la autonomía de los padres y allegados, sin por ello declinar la asistencia de las administraciones. Se trata, en definitiva, de favorecer la constitución de estas masas de bienes que puedan estar afectados a garantizar, sin perjuicio de la garantía pública que en cualquier caso existirá, la asistencia y calidad de vida de los discapacitados. 
forma se atiende a la preocupación de muchas familias que quieren prever la situación en que quedará su familiar discapacitado cuando los progenitores o tutores ya no estén o ya no puedan hacerse cargo de él, sin perjuicio de que el Estado despliegue la necesaria función asistencial cuando proceda.

Respecto a la nueva figura del patrimonio especialmente protegido, pueden ser beneficiarios del mismo el discapacitado afectado por una minusvalía psíquica igual o superior al $33 \%$, o los afectados por una minusvalía física y sensorial igual o superior al $65 \%$.

Pueden constituir este patrimonio, o bien la propia persona con discapacidad que vaya a ser beneficiaria del mismo o, en caso de que esta no tenga plena capacidad de obrar, sus padres o tutores, haciendo una aportación de bienes o derechos. En caso de negativa por parte de estos, esa persona puede solicitar su constitución al juez de causa. La administración del patrimonio protegido se regula con gran flexibilidad, de forma que podrá corresponder a quien constituya el patrimonio, sea la propia persona con discapacidad, sean sus padres. Esta administración podrá también confiarse, si así lo decide el constituyente, a terceras personas o a instituciones sin ánimo de lucro especializadas en la gestión de este tipo de patrimonios. Salvo en los casos en que haya constituido el patrimonio el propio discapacitado, las reglas de administración deberán prever que se requiera autorización judicial en los mismos supuestos que, en la actualidad, la requiere el tutor respecto de los bienes del tutelado, si bien se permite que el juez pueda flexibilizar este régimen.

La ley regula también la extinción del patrimonio protegido, que se producirá por fallecimiento de la persona con discapacidad o porque esta deje de padecer una minusvalía en los grados establecidos para ser beneficiario. La supervisión de la administración del patrimonio protegido corresponde al Ministerio Fiscal, al que deberá rendir cuentas de su gestión el administrador del patrimonio. Como órgano de apoyo y auxilio del Ministerio Fiscal se creará una Comisión de Protección Patrimonial de las Personas con Discapacidad, adscrita al Ministerio de Trabajo y Asuntos Sociales, en la que participarán representantes de la asociación más representativa de los diferentes tipos de discapacidad. Esta Comisión llevará el Registro de Patrimonios Protegidos.

\section{EL DOCUMENTO PÚBLICO NOTARIAL}

En lo que respecta a la naturaleza jurídica de la autotutela, tiene las siguientes características primordiales:

a) Nos encontramos ante un negocio jurídico unilateral, porque la declaración negocial procede "ex uno latere", sin que, por tanto, se necesite para su perfección de la aceptación de nadie ni de ninguna otra parte. 
b) Para la producción de los efectos requiere la formalidad, esto es, que la declaración de voluntad sea notificada; es decir, comunicada oficialmente y, por tanto, se acredita que ha sido dada a conocer a otra persona.

c) Tiene carácter personalísimo, porque solo puede ser llevada a efecto por el propio interesado, sin que sea delegable su realización en un tercero.

d) Es un negocio jurídico inter vivos, porque ha de producir sus efectos siempre en vida del declarante y nunca mortis causa.

e) Siendo solemne, en tanto que, para su validez, debe recogerse siempre en documento público notarial.

f) Es revocable, al igual que sucede con el testamento.

El Art. 9 de la Ley 41/2003, de 18 noviembre, que modifica el Art. 223 del Código Civi$1,{ }^{16}$ establece que la autotutela se instrumentará en documento público notarial. Ello supone que la actual legislación espańola establece una formalidad, y no admite que la figura de la autotutela se articule mediante documento privado, lo cual permite que el notario dé fe respecto a si el interesado, en el momento de firmar el documento, tiene realmente capacidad de obrar suficiente para ello, circunstancia que no podría controlarse en caso de que se admitiera que la autotutela se instrumentara en documento privado, lo que podría dar lugar a situaciones no deseadas, como por ejemplo que una persona interesada en administrar el patrimonio de quien ya es incapaz realice un documento en el que le obligue a firmar su designación como tutor o que incluso falsifique la firma del supuesto capaz.

Con anterioridad a la publicación de la referida ley, algunos de los defensores de la autotutela se manifestaban a favor de que la misma pudiera quedar recogida en testamento. Sin embargo, esta posibilidad tiene que ser descartada por razones obvias, ya que la designación hecha por el interesado tiene que surtir efectos durante la vida de este (en caso de que alcance la situación de incapacidad) y no después del fallecimiento. Solo podrá recurrirse al testamento para la designación de tutor en el supuesto de que sean los padres los que realicen la designación respecto de sus hijos, tal y como establece el Art. 223 del Código Civil, pero no para los supuestos de autotutela.

16 El propio legislador en su Exposición de Motivos nos dice que la autotutela “... se regula introduciendo unos cambios mínimos en el Código Civil, consistentes en habilitar a las personas capaces para adoptar las disposiciones que considere oportunas en previsión de su propia incapacitación, y ello en el mismo precepto que regula las facultades parentales respecto de la tutela, y en alterar el orden de delación de la tutela, prefiriendo como tutor en primer lugar al designado por el propio tutelado, si bien sin modificar la facultad genérica que corresponde al juez de alterar el orden de delación cuando así convenga al interés del incapacitado, pero siempre que hayan sobrevenido circunstancias que no fueron tenidas en cuenta al efectuar la designación”. 
Dentro de los distintos tipos de documentos públicos notariales, parece claro que el más apropiado para instrumentar la autotutela es la escritura, ya que es el documento propio destinado a ilustrar la manifestación de la voluntad, garantizando los datos de identificación del interesado, su juicio de capacidad y la legalidad de los contenidos recogidos en el documento público.

La escritura que recoge la autotutela es una manifestación de la voluntad del (posible) futuro incapaz y podrá referirse no solo a la designación del tutor o tutores, sino que también podrá contener disposiciones de carácter patrimonial, ya que el apartado segundo del Art. 223 del Código Civil establece que el documento público podrá tener disposiciones relativas a los bienes del posible futuro incapaz.

El interesado, a la hora de formular su autotutela, tiene varias posibilidades en cuanto a la designación de tutor. Resulta posible que designe como tutor bien a una persona jurídi$\mathrm{ca},{ }^{17}$ bien a una persona física; ${ }^{18}$ puede optar por una designación individual o bien por una designación conjunta, en cuyo caso los diversos tutores podrán actuar de forma solidaria o mancomunada. ${ }^{19}$ Se admite también que la escritura de autotutela recoja disposiciones tutelares alternativas para el caso de que los llamados a ocupar el cargo de tutor no estén en condiciones de aceptarlo. Se permite asimismo que en la escritura se nombre a quien no se desea que ocupe tal puesto, posibilidad que deriva de una aplicación analógica del Art. 245 del Código Civil.

Aunque según lo dispuesto en el Art. 234 del Código Civil, el juez, dentro del procedimiento de incapacitación (llegado el caso), tendrá que nombrar tutor en primer lugar a quien el incapaz hubiere designado, el precepto referido así como el Art. 235 de la misma norma facultan al juez a designar a un tutor diferente cuando considere que ello redundará en el beneficio del incapaz.

La doctrina parece unánime en la posibilidad de que el interesado, antes de que se produzca la declaración de incapacitación, modifique (bien de forma total, bien de forma parcial) las designaciones tutelares que hubiera hecho, así como lo que hubiera ordenado respecto de su persona y sus bienes en la escritura pública de autotutela, para lo cual será necesario una nueva escritura, salvaguardando "la voluntad" como un elemento esencial del acto jurídico.

Entre las causas de extinción de la autotutela pueden citarse de forma somera las siguientes: muerte del incapaz (Art. 276.3 del Código Civil); extinción de la incapacitación por

17 Art. 242 del Código Civil español.

18 Art. 241 del Código Civil español.

19 Art. 247 del Código Civil español. 
resolución judicial (Art. 277.2 del Código Civil); muerte o incapacidad del tutor designado cuando no hubiera previsto sustituto; inhabilitación del tutor para seguir ejerciendo el cargo cuando no se hubiera previsto sustituto; y cumplimiento del plazo por el cual fue nombrado el tutor sin que se hubiera previsto sustituto.

\section{CONCLUSIONES}

$\mathrm{Al}$ abordar la legislación espańola en torno al concepto denominado autotutela, destacan los efectos altamente positivos de otorgar de manera expresa a una persona la facultad de tomar decisiones sobre la fortuna, señalando la finalidad de esta, y que entre otras cosas puede ser para su asistencia personal, en el infortunio de una enfermedad o para su tratamiento médico. Se debe decidir en beneficio siempre del tutorado, con el grado de precisión socialmente humano que considere determinar el mejor modo de administración de su patrimonio, en el momento en que aún tiene determinada autonomía personal, con la finalidad no disimulada de que pueda ir generando su eficacia de modo progresivo con anterioridad al momento en que el resto de la familia piense en la posibilidad de su incapacitación.

Se trata de buscar las fórmulas jurídicas más adecuadas para posibilitar el tránsito progresivo de la autonomía personal plena a la dependencia de terceros y conseguir que el propio afectado, que es el principal interesado, pueda tener la tranquilidad que gestiona desde el comienzo, a su entera voluntad, el desarrollo de este proceso, aún después de que se pierda la conciencia o la capacidad física.

A manera de crítica, y buscando el perfeccionamiento con miras a la posibilidad de incluir esta figura en la mayoría de nuestra legislación mexicana, existe en la disyuntiva de la interpretación o el objetivo real de encontrarnos en las leyes existentes una definición de lo que es autotutela, para ello considero que debemos acudir al preámbulo de la misma, ya que a lo largo de su articulado no aparece ninguna definición, no pasando por alto la parte medular y sensible que conlleva. También plantea problemas interpretativos la dicción literal del articulado cuando se refiere a "cualquier persona con la capacidad de obrar suficiente", y se permite, de acuerdo al código sustantivo, no solo a los mayores de edad sino también a los menores de edad emancipados, pero sin que quede suficientemente claro por la falta de rigor del legislador en esa expresión, formando con esto una limitante interpretativa.

No obstante, a pesar de cualquier deficiencia de la que pueda adolecer la normativa española, es destacable la institución de la autotutela como un medio a través del cual los miembros de la sociedad pueden decidir, en el uso de sus facultades y como prerrogativa del ejercicio de sus derechos personales, la forma en que serán atendidos (y por quién) en caso de una incapacidad futura. 


\section{REFERENCIAS}

- Carlos Rendón Ugalde, "Fundamentos teóricos y prácticos de la autotutela", Revista de Derecho Privado, no 11 (2005). Acceso: octubre de 2015.

https://revistas-colaboracion.juridicas.unam.mx/index.php/derecho-privado-ns/article/ view/7180/6459

- Código Civil, publicado por el Real Decreto de 24 de julio de 1889. Boletín Oficial del Estado, n. 206 (julio de 1889). Referencia BOE-A-1889-4763. Acceso: octubre de 2015. http://www.boe.es/buscar/pdf/1889/BOE-A-1889-4763-consolidado.pdf

- Diccionario de la Real Academia de la Lengua Española. Acceso: octubre de 2015. http://dle.rae.es/?w=ortotanasia\&o=h

- Exposición de motivos de la Ley 43/2003, de Protección Patrimonial de las Personas con Discapacidad, publicada el 18 de noviembre de 2003. Acceso: octubre de 2015. http://www.boe.es/buscar/act.php?id=BOE-A-2003-21053

- Ley 41/2003, de 18 de noviembre, de protección patrimonial de las personas con discapacidad y de modificación del Código Civil, de la Ley de Enjuiciamiento Civil y de la Normativa Tributaria con esta finalidad, publicada el 19 de noviembre de 2003. En Boletín Oficial del Estado, $\mathrm{N}^{\circ}$ 277. Departamento Jefatura del Estado. Referencia BOE-A-2003-21053. Acceso: octubre de 2015.

https:/www.boe.es/buscar/act.php?id=BOE-A-2003-21053

- Ley de Voluntad Anticipada para el Distrito Federal, publicada el 07 de enero de 2008. En Gaceta Oficial del Distrito Federal. Acceso: octubre de 2015. http://www.aldf.gob.mx/archivo-077346ece61525438e126242a37d313e.pdf

RECIBIDO: $21 / 11 / 2018$

APROBADO: $19 / 05 / 2019$ 


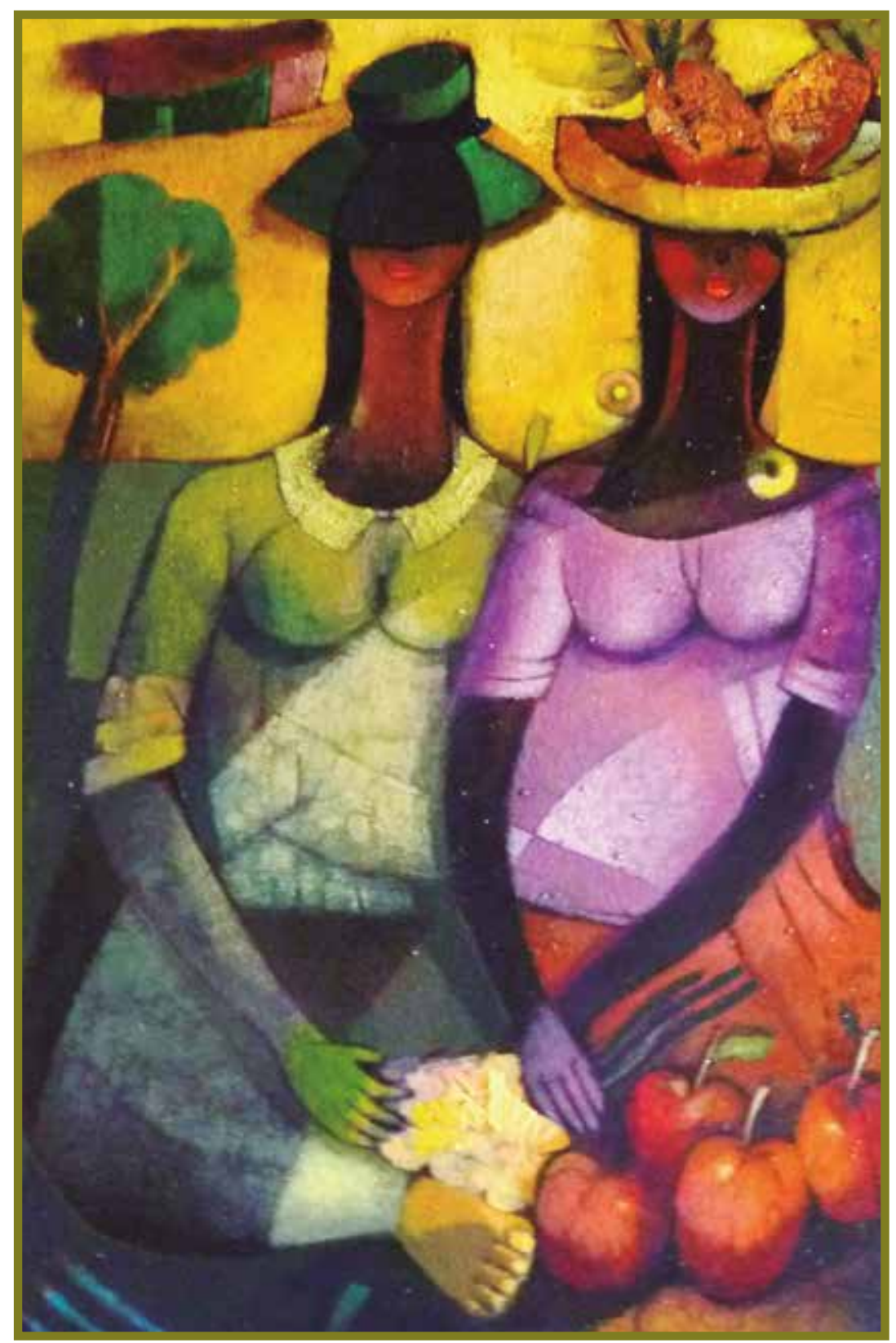

Vendedoras en el mercado. Óleo.

Agustín Aquino Mejías (pintor peruano). 